\title{
Storage Temperature Influences the Carbamide Peroxide Concentration of at Home Bleaching Agents
}

\author{
Francine Kerber Vieira Makwitz ${ }^{1}$, Celso Afonso Klein Junior*2, Eduardo Galia Reston², Rubem Beraldo dos Santos ${ }^{2}$, \\ Fernando Freitas Portella ${ }^{3}$ and Keiichi Hosaka ${ }^{4}$
}

${ }^{1}$ Department of Operative Dentistry, School of Dentistry, Lutheran University of Brazil, Brazil

${ }^{2}$ Department of Operative Dentistry, School of Dentistry, Lutheran University, California

${ }^{3}$ Post-doctoral researcher, School of Dentistry, Lutheran University, Japan

${ }^{4}$ Assistent professor, Department of Oral Health Science, School of Medical and Dental Science, Japan

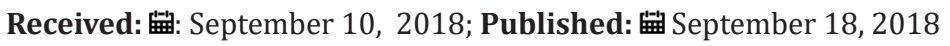

*Corresponding author: Celso Afonso Klein Junior, Department of Operative Dentistry, School of Dentistry, Lutheran University, Brazil

\begin{abstract}
This study aimed to evaluate the influence of storage temperature on the maintenance of bleaching agent concentration and whether concentrations are within the recommendations of the International Standard for products for external tooth bleaching. The samples consisted of ten commercially manufactured and four compounded tooth whitening gels. Hydrogen peroxide and carbamide peroxide bleachin agents at different concentrations were included on analysis. The United States Pharmacopeia and International Standard methods was used to determine the amount of peroxide, in the agents of different brands and concentrations after products storage at $3^{\circ} \mathrm{C}, 20^{\circ} \mathrm{C}$ and $40^{\circ} \mathrm{C}$ by 8 days. Analysis was repeated 8 times for each temperature. Differences between means was analyzed by ANOVA and Tukey test at $1 \%$ of significance. In general, storage at hot temperatures decreases the peroxide concentration. None of the tested bleaching agents match the labeled peroxide concentration, especially those based on carbamide peroxide from dispensing pharmacy that has differences less than $30 \%$ from labeled. These findings indicate that the storage temperature influences the concentration of the peroxides tested.
\end{abstract}

Keywords: Tooth Bleaching; Peroxides; Hydrogen Peroxide; Drug Stability

\section{Introduction}

Tooth whitening is increasingly requested by many patients. The degree of efficacy and speed of action of tooth bleaching depend on some variables, including the concentration of the active ingredient and the contact time of the product with the tooth surface [1]. A recent study on hydrogen peroxide- and carbamide peroxide-based bleaching systems has shown that tooth whitening is safe and effective when the manufacturer's instructions are followed, and that both the dental practitioner and the patient should be aware of the care plan and risks involved [2]. The efficacy and safety of commercial bleaching agents have been demonstrated in several studies using trays with different concentrations of carbamide peroxide, ranging from 10 to $16 \%$, and hydrogen peroxide, ranging from 7.5 to $9.5 \%$ [1,3-9]. Long-term or high-temperature storage and faulty packaging, among other problems, can cause bleaching gels to lose potency [10]. The penetration of hydrogen peroxide is enhanced by increasing the residence time of the product on the tooth surface, and, after 45 minutes, products significantly reduce the concentration of hydrogen peroxide [11]. Some manufacturers recommend that bleaching gels should be stored within a maintenance temperature range, which may vary by a few degrees according to specifications described in the package insert. When this fact is not considered, it may lead to a faster degradation of bleaching agents and a change in the $\mathrm{pH}$ of the active agent both of in-office and at-home bleaching products [12].

A previousstudy [12] evaluated whether the actual concentration of bleaching agents available in four different countries was the same as the label indicated and within the recommendations of the International Standard on tooth whitening. All products in the United States and China were within the recommendations of the International Standard when products were tested immediately upon delivery at testing sites. One product in Saudi Arabia and three products in Brazil had greater than 30\% concentration loss [13]. There is a specific requirement that tooth bleaching products must have their concentration and expiration date indicated on the label, and that the actual concentration of the active ingredient should not exceed $10 \%$ or be less than $30 \%$ of the concentration indicated by the manufacturer on the useful life of the product [14]. In an analysis of the concentration of $16 \%$ carbamide peroxide-based 
products prepared at different compounding pharmacies and of a commercial bleaching product, only the commercial bleaching product and one of the compound products showed the best mean concentration values, close to $16 \%$ [15].

Likewise, some authors evaluated the concentration of commercial bleaching agents and showed that even commercially available products also had concentrations that differed from the values specified by the manufacturer in the package insert $[1,16,17]$. Thus, the aim of the present study was to assess the peroxide concentration of commercially manufactured and compounded bleaching agents and evaluate the influence of storage temperature on peroxide concentration.

\section{Material and Methods}

The samples consisted of commercially manufactured and compounded tooth whitening gels of different brands and at different concentrations. Tested materials were presented at (Table 1). Commercial bleaching products were purchased from dental supply houses in Brazil, and we chose products that can be easily found by and are readily available to dental practitioners. Compound products were prepared in a dispensing pharmacy accredited by the University were the study was performed. Commercial bleaching agents were analyzed in the first three months after manufacturing, and compound products were analyzed in the first week after preparation.

Table 1: Peroxide concentration (\%) of bleaching agents according storage temperature.

\begin{tabular}{|c|c|c|c|c|c|c|c|}
\hline \multirow{3}{*}{$\begin{array}{c}\text { Product } \\
\text { (manufacturer) }\end{array}$} & \multirow{3}{*}{$\begin{array}{c}\text { Type of } \\
\text { peroxide } \\
\text { and labeled } \\
\text { concentration }\end{array}$} & \multicolumn{6}{|c|}{ Storage temperature } \\
\hline & & \multicolumn{2}{|c|}{$3^{\circ} \mathrm{C}$} & \multicolumn{2}{|c|}{$20^{\circ} \mathrm{C}$} & \multicolumn{2}{|c|}{$40^{\circ} \mathrm{C}$} \\
\hline & & Mean (SD) & $\begin{array}{l}\text { Difference (\%) } \\
\text { from labeled }\end{array}$ & Mean (SD) & $\begin{array}{l}\text { Difference (\%) } \\
\text { from labeled }\end{array}$ & Mean (SD) & $\begin{array}{l}\text { Difference (\%) } \\
\text { from labeled }\end{array}$ \\
\hline $\begin{array}{l}\text { White Class (FGM, } \\
\text { Joinville, PR, Brazil) }\end{array}$ & HP 6\% & $5.34(0.08)^{\mathrm{A}}$ & -11 & $5.02(0.02)^{\mathrm{B}}$ & -16.33 & $5.00(0.17) \mathrm{B}$ & -16.67 \\
\hline $\begin{array}{l}\text { White Class (FGM, } \\
\text { Joinville, PR, Brazil) }\end{array}$ & HP 7.5\% & $7.07(0.14)^{\mathrm{A}}$ & -5.73 & $7.27(0.22)^{\mathrm{A}}$ & -3.07 & $7.11(0.16)^{\mathrm{A}}$ & -5.2 \\
\hline $\begin{array}{l}\text { White \& Brite Night } \\
\text { (3M ESPE, St. Paul, MN, } \\
\text { USA) }\end{array}$ & CP $10 \%$ & $8.07(0.20)^{\mathrm{B}}$ & -19.3 & $9.40(0.23)^{\mathrm{A}}$ & -6 & $8.07(0.18)^{\mathrm{B}}$ & -19.3 \\
\hline $\begin{array}{l}\text { White \& Brite Night } \\
\text { (3M ESPE, St. Paul, MN, } \\
\text { USA) }\end{array}$ & CP $16 \%$ & $14.40(0.19)^{\mathrm{B}}$ & -10 & $15.50(0.21)^{A}$ & -3.13 & $13.5(0.99)^{\mathrm{C}}$ & -15.63 \\
\hline $\begin{array}{l}\text { Power Bleaching (BM4, } \\
\text { Maringá, PR, Brazil) }\end{array}$ & CР $10 \%$ & $6.81(0.10)^{\mathrm{B}}$ & $-31.90 \#$ & $8.06(0.11)^{\mathrm{A}}$ & -19 & $6.24(0.34)^{\mathrm{B}}$ & $-37.60 \#$ \\
\hline $\begin{array}{l}\text { Power Bleaching (BM4, } \\
\text { Maringá, PR, Brazil) }\end{array}$ & СР $16 \%$ & $14.60(0.43)^{\mathrm{A}}$ & -8.75 & $14.60(0.18)^{A}$ & -8.75 & $12.10(0.19)^{\mathrm{B}}$ & -24.38 \\
\hline $\begin{array}{c}\text { Whiteness Perfect } \\
\text { (FGM, Joinville, PR, } \\
\text { Brazil) }\end{array}$ & СР 10\% & $8.94(0.12)^{\mathrm{B}}$ & -10.6 & $10.20(0.11)^{\mathrm{A}}$ & 2 & $8.88(0.26)^{\mathrm{B}}$ & -11.2 \\
\hline $\begin{array}{c}\text { Whiteness Perfect } \\
\text { (FGM, Joinville, PR, } \\
\text { Brazil) }\end{array}$ & СР $16 \%$ & $14.90(0.24)^{\mathrm{B}}$ & -6.88 & $16.10(0.22)^{\mathrm{A}}$ & 0.63 & $14.20(0.32)^{\mathrm{B}}$ & -11.25 \\
\hline $\begin{array}{l}\text { Opalescence (Ultradent, } \\
\text { South Jordan, UT, USA) }\end{array}$ & СР $10 \%$ & $9.78(0.19)^{\mathrm{A}}$ & -2.2 & $9.85(0.29)^{A}$ & -5 & $9.15(0.34)^{\mathrm{B}}$ & -8.5 \\
\hline $\begin{array}{l}\text { Opalescence (Ultradent, } \\
\text { South Jordan, UT, USA) }\end{array}$ & СР 15\% & $14.00(0.23)^{A}$ & -6.67 & $14.0(0.35)^{\mathrm{A}}$ & -6.67 & $13.10(0.24)^{\mathrm{A}}$ & -12.67 \\
\hline $\begin{array}{c}\text { Compound A } \\
\text { (dispensing pharmacy) }\end{array}$ & HP 6\% & $5.34(0.11)^{\mathrm{B}}$ & $-11,00$ & $5.89(0.12)^{\mathrm{A}}$ & -1.83 & $5.09(0.12)^{\mathrm{C}}$ & -6.83 \\
\hline $\begin{array}{c}\text { Compound B } \\
\text { (dispensing pharmacy) }\end{array}$ & HP 7.5\% & $7.40(0.15)^{\mathrm{A}}$ & -1.33 & $6.60(0.11)^{\mathrm{C}}$ & -12 & $6.93(0.06)^{\mathrm{B}}$ & -0.93 \\
\hline $\begin{array}{c}\text { Compound C } \\
\text { (dispensing pharmacy) }\end{array}$ & СР $10 \%$ & $4.81(0.13) \mathrm{A}$ & $-51.90 \#$ & $4.61(0.24) \mathrm{A}$ & $-53.90 \#$ & $3.75(0.07) \mathrm{A}$ & $-62.50 \#$ \\
\hline $\begin{array}{c}\text { Compound D } \\
\text { (dispensing pharmacy) }\end{array}$ & СР 16\% & $7.06(0.21) \mathrm{A}$ & -29.4 & $6.81(0.14) \mathrm{A}$ & $-57.44 \#$ & $6.15(0.06) \mathrm{A}$ & $-38.50 \#$ \\
\hline
\end{tabular}

Note: Means followed by distinct letter indicates statistical difference $(p<0,010)$ in the same row. HP: hydrogen peroxide; $C P$ : carbamide peroxide; SD: standard deviation. \#Indicate values that did not attend ISO 28399. 


\section{Peroxide Concentration Analysis}

The method recommended for assaying peroxide by the United States Pharmacopeia [18] and International Standard [14] was used to determine the amount of peroxide in the bleaching agents. The specific steps taken in the present chemical analysis have been used previously in several studies [10,13,19-22]. All products were stored at room temperature upon arrival at the university and maintained in separate groups until analysis. Each bleaching agent was analysed in all the temperatures: room temperature $\left(20^{\circ} \mathrm{C}\right)$, warm $\left(40^{\circ} \mathrm{C}\right)$ and $\mathrm{cool}\left(3^{\circ} \mathrm{C}\right)$. Storage temperatures were simulated by heating at $40^{\circ} \mathrm{C}$ in a microbiological incubator; and cooling at $3^{\circ} \mathrm{C}$ in a refrigerator; both storages were maintained for 8 days. The peroxide concentration was determined by iodometric titration using sodium thiosulfate as titrant. The data analysis of the curve obtained using this method showed small variations in concentration during the test period, accounting for the actual error of the method, which is of approximately $0.1 \%$. It was considered that by day 8 there was a significant reduction in the peroxide concentration of the sample, with no significant reduction thereafter.

Initially, an empty test tube of $250 \mathrm{~mL}$ was weighed on an analytical balance (Bioprecisa, Curitiba, PR, Brazil) accurate to four decimal places. Approximately $0.2500 \mathrm{~g}$ of the tooth whitening product was placed in the empty test tube, which was weighed again. The weight of the sample was calculated by subtracting the weight of the empty test tube from that of the tube containing the sample. The balance was tared before each measurement. Deionized water was added up to the $100-\mathrm{mL}$ mark on the tube. A stir bar was placed in the tube, and the sample was stirred using a magnetic stirrer (Fisatom, São Paulo, SP, Brazil) until a homogeneous solution was obtained. Then, $20 \mathrm{~mL}$ of glacial acetic acid were added to the solution. Approximately $2 \mathrm{~g}$ of potassium iodide were added to the solution and allowed to dissolve, which turned the color of the solution to a light shade of yellow. Three drops of ammonium molybdate were added, and the solution was allowed to stand until it became homogeneous again. The tube was then covered with a dark hood for at least 10 minutes to allow the chemicals to fully associate, accompanied by a color change in the solution, thus ensuring complete reaction with the available peroxide.

Gradually, $0.025 \mathrm{~N}$ of sodium thiosulfate were titrated into the solution using a 50 -mL burette until the color of the sample changed to pale yellow. Then, $3 \mathrm{~mL}$ of a $1.0 \%$ starch indicator were added to the solution, which turned the color of the solution to dark purple. More sodium thiosulfate was titrated into the solution using a 50$\mathrm{mL}$ burette until the solution turned colorless, which was the end point of the assay. Sodium thiosulfate was essential for the chemical analysis because it determined the concentration and quality of the analysis. The color changes that occurred throughout the chemical analysis were the result of the steps of the assay, thus indicating complete reaction with the available peroxides. The concentration of the bleaching agent was determined by the following formulas: Carbamide Peroxide (CP)\% $=4.704 \times \mathrm{STmL} \times(0.025 / \mathrm{PWg})$ and Hydrogen peroxide (HP) $\%=1.704 \mathrm{X}$ TSml X $(0.025 / \mathrm{PWg})$.

\section{Statistical Analysis}

Each measure was repeated eight times and the mean value and standard deviation was calculated to each bleaching agent. Analysis of variance (ANOVA) followed by Tukey post-hoc test was used to compare group means at the different storage temperatures at $1 \%$ significance level.

\section{Results}

The mean concentration values of each tooth bleaching product analyzed at the three different storage temperatures are shown in Table 1. Of 10 commercial bleaching products analyzed, nine showed statistically significant differences in concentration $(p<0.001)$ when compared to each other at the three storage temperatures; only White Class $7.5 \%$ hydrogen peroxide showed no statistically significant difference $(p=0.079)$. Of four compound products analyzed, all showed statistically significant differences in concentration $(\mathrm{p}<0.001)$ when compared to each other at the three temperatures. Regarding the requirements of the International Standard for products for external tooth bleaching, of 10 commercial bleaching products assayed, nine met the requirements; warm- and cold-stored products in Power Bleaching, $10 \%$ carbamide peroxide had concentrations lower than those accepted by the International Standard, with greater than $30 \%$ loss of the active agent concentration indicated by the manufacturer.

Among the four compound products assayed, two met the requirements of the International Standard, while two products, $10 \%$ and $16 \%$ carbamide peroxide), at room, warm, and cold storage temperatures, had concentrations lower than those accepted by the International Standard, with greater than $30 \%$ loss of the active agent concentration indicated by the compounding pharmacy. With respect to storage temperatures, White \& Brite Night $10 \%$ carbamide peroxide and Whiteness Perfect $10 \%$ carbamide peroxide did not differ in concentration between highand low-temperature storage. However, there was a statistically significant difference $(p<0.001)$ when comparing these two storage temperatures with room temperature. Likewise, the bleaching products White \& Brite Night 16\% carbamide peroxide, Power Bleaching 10\% carbamide peroxide, Whiteness Perfect 16\% carbamide peroxide, compound product $10 \%$ carbamide peroxide, compound product $16 \%$ carbamide peroxide, compound product $6 \%$ hydrogen peroxide and compound product $7.5 \%$ hydrogen peroxide, at all three storage temperatures showed statistically significant differences between each other $(\mathrm{p}<0.001)$.

Conversely, products Power Bleaching 16\% carbamide peroxide, Opalescence $10 \%$ carbamide peroxide, and Opalescence $15 \%$ carbamide peroxide did not differ in concentration between room- and cold-temperature storage but were statistically different from warm-stored products $(\mathrm{p}<0.001)$. However, in White Class $6 \%$ hydrogen peroxide, products stored at room and warm temperatures did not differ in concentration but were statistically different from cold-stored products $(\mathrm{p}<0.001)$. 


\section{Discussion}

Esthetics has been a topic of interest since the beginning of civilization [22]. Over the years, patients are increasingly asking for tooth whitening. It is well known and accepted that the effectiveness of bleaching agents is dependent on the contact time between the agent and tooth surface and on the peroxide concentration [13]. The actual concentration of bleaching agents compared to the labeled concentration has been investigated by several authors $[1,13,15,17,19-23]$. who have shown results for the concentration of the active agent different from those specified by the manufacturers. These findings are consistent with the present study, in which the concentration of the active agent was statistically different when the products were compared to each other at the three storage temperatures, which may render products less clinically effective than expected, thus probably failing to achieve an effective clinical outcome. The Clinical Research Associates [10] have stated that "storage for extended time or in warm temperature, faulty packaging, and other problems can cause bleaches to lose potency."

In agreement with this statement, of 14 products tested in the present study, 13 showed statistically significant differences in concentration $(\mathrm{p}<0.001)$ when compared to each other at three storage temperatures (room, warm, and cold). Only White Class $7.5 \%$ hydrogen peroxide had no statistically significant difference in concentration ( $p=0.079)$, showing that the variation in temperature affected the stability of the concentration of the peroxides tested, and heat induced a greater difference in concentration in most products analyzed. Similar to the studies of Matis et al [13]. and Clinical Research Associates [10] the changes in peroxide concentration may be attributed to storage, warm temperatures, faulty packaging, and transportation, among other problems. Since this variation exists, the dentist's and the patient's experience are negatively affected both in quality and safety. According to the requirements of the International Standard [14] tooth bleaching products must have the percentage of concentration and expiration date indicated on the label, and the actual concentration of the active ingredient should not be above $10 \%$ or below $30 \%$ of the concentration indicated by the manufacturer.

Of the 10 commercial bleaching products analyzed in the present study, nine met the requirements of the International Standard for products for external tooth bleaching. Of the four compound products assayed, two met these requirements. However, it should be noted that their actual concentration was not in agreement with the concentration indicated by the manufacturer, as previously mentioned. Therefore, in the current study, one commercial bleaching product, Power Bleaching 10\% carbamide peroxide, at warm and cold storage temperatures, had concentrations lower than those accepted by the International Standard, with greater than $30 \%$ loss of the active agent concentration indicated by the manufacturer. At high-temperature storage, the concentration loss was increased, which may influence the stability of the product concentration. The concentration of bleaching agents in previously tested products has ranged from 1.08 above to 3.55 below the concentrations indicated by the manufacturer $[1,16]$. In the present study, when analyzing commercially available bleaching products, there were differences in concentration at room temperature $(1.94$ below and 0.2 above), warm temperature ( 3.90 below) and cold temperature (3.19 below) from the percentages of concentration indicated on the label. Manufacturers need to more appropriately adjust the peroxide stability, so that bleaching products can be distributed and stored in countries with large territory and thermal variation without causing peroxides to lose stability.

We cite the example of Brazil, a large country located between the Equator and the Southern Tropic.The worst results of the present study were obtained with compound products containing carbamide peroxide, which are consistent with the study of Martin et al [15]. who also tested compound carbamide peroxide-based products and found different concentration values in relation to the labeled concentration. In the current study, in two compound products, $10 \%$ and $16 \%$ carbamide peroxide, at room, warm, and cold storage temperatures, the optimal concentration of the active ingredient had greater than $30 \%$ loss of the concentration specified by the manufacturer, indicating concentration values lower than those accepted by the International Standard and demonstrating the large variation in the concentration of compounded carbamide peroxides at the three storage temperatures. At high-temperature storage, the concentration loss was increased, which may lead to increased release of oxygen, thereby impairing the product's clinical performance. The variation in the peroxide concentration of these compound products should not occur in the group tested at room temperature, since this group was not subjected to temperature variation from preparation to the time of analysis.

Further studies are warranted to investigate the quality of thickeners or even stabilizers used in compounded peroxides. Customers have no way to find out the actual concentration of the active agent in these products, or even in commercial beaching products. Patients only have access to the information provided in the package insert and believe that the product will remain stable during storage. Differences from the labeled concentration may occur during the manufacturing, transportation or storage of tooth whitening products, leading to a faster degradation of bleaching agents [13]. In the present study, products Power Bleaching 16\% carbamide peroxide, Opalescence 10\% carbamide peroxide, and Opalescence 15\% carbamide peroxide, in relation to storage temperatures, did not differ from each other at room and cold temperatures, but were statistically different from warmstored products $(\mathrm{p}<0.001)$, indicating that heat influences the maintenance of the peroxide concentration. In Brazil, the climate is extremely tropical, with very hot as well as very cold seasons, depending on the climate in each state.

Thus, industries and distributors should review their logistics for the delivery of tooth whitening products, which should be handled as drugs, in the same way as vaccines, to avoid the risk of affecting their clinical performance. The efficacy and safety of bleaching agents have been demonstrated in different studies [1,3-9]However, for greater efficacy and safety, tooth whitening products should be inspected by the manufacturers themselves, from transportation to storage, because temperature variation, as described in the present study, may have an effect on the peroxide 
concentration, leading to a faster degradation of active agents. Thus, given the lack of studies assessing the influence of thermal changes at three different storage temperatures (room, warm, and cold) on the concentration of peroxides, the present results are of great importance.

\section{Conclusion}

Temperature variation affected the concentration of the peroxides in this study. The tested products showed different results for the concentration of the active agent when compared to each other at three storage temperatures (room, warm, and cold). None of the tested bleaching agents match the labeled peroxide concentration, especially those based on carbamide peroxide from dispensing pharmacy that has differences less than $30 \%$ from labeled, failing to meet the requirements of the International Standard for products for external tooth bleaching.

\section{References}

1. Matis BA (2003) Tray whitening: what the evidence shows. Compend Contin Educ Dent 24(4A): 354-362.

2. Carey CM (2014) Tooth whitening: what we now know. J Evid Based Dent Pract 14: 70-76.

3. Leonard RH, Sharma A, Haywood VB (1998) Use of different concentrations of carbamide peroxide for bleaching teeth: an in vitro study. Quintessence Int 29(8): 503-507.

4. Joiner A, Thakker G (2004) In vitro evaluation of a novel 6\% hydrogen peroxide tooth whitening product. J Dent 32 Suppl 1: 19-25.

5. Meireles SS, Heckmann SS, Santos IS, Della Bona A, Demarco FF, et al. (2008) A double blind randomized clinical trial of at-home tooth bleaching using two carbamide peroxide concentrations: 6-month follow-up. J Dent 36(11): 878-884.

6. Meireles SS, Heckmann SS, Leida FL, dos Santos Ida S, Della Bona A, et al. (2008) Efficacy and safety of $10 \%$ and $16 \%$ carbamide peroxide toothwhitening gels: a randomized clinical trial. Oper Dent 33(6): 606-612.

7. Sulieman MA (2008) An overview of tooth-bleaching techniques: chemistry, safety and efficacy. Periodontol 2000 48: 148-169.

8. Meireles SS, Fontes ST, Coimbra LA, Della Bona A, Demarco FF, et al. (2012) Effectiveness of different carbamide peroxide concentrations used for tooth bleaching: an in vitro study. J Appl Oral Sci 20(2): 186191.

9. Alonso de la Pena V, Lopez Raton M (2014) Randomized clinical trial on the efficacy and safety of four professional at-home tooth whitening gels. Oper Dent 39(2): 136-143.

\section{ISSN: 2574-1241}

DOI: $10.26717 / B J S T R .2018 .09 .001750$

Celso Afonso Klein Junior. Biomed J Sci \& Tech Res

This work is licensed under Creative

Commons Attribution 4.0 License

Submission Link: https://biomedres.us/submit-manuscript.php
10. Clinical Research Associates (1997) Tooth bleaching, state of- art '97. Clinical Research Associates Newsletter 21(4): 2.

11. Marson FC, Goncalves RS, Silva CO, Cintra LT, Pascotto RC, et al. (2015) Penetration of hydrogen peroxide and degradation rate of different bleaching products. Oper Dent 40(1): 72-79.

12. Freire A, Archegas LR, de Souza EM, Vieira S (2009) Effect of storage temperature on $\mathrm{pH}$ of in-office and at-home dental bleaching agents. Acta Odontol Latinoam 22(1): 27-31.

13. Matis BA, Matis JI, Wang Y, Monteiro S, Al Qunaian TA, et al. (2013) Labeled vs actual concentration of bleaching agents. Oper Dent 38(3): 334-343.

14. International Organization of Standardization (2011) ISO Standards ISO/FDIS 28399. Dentistry - Products for external tooth bleaching. International Organization of Standardization, Geneve, Switzerland.

15. Martin JM, Torno V, Vaz MV, Vieira S, Rosa EA, et al. (2007) Specific concentration evaluation of $16 \%$ carbamide peroxide compounded at dispensing pharmacies. Braz Oral Res 21(4): 318-322.

16. Matis BA (2000) Degradation of gel in tray whitening. Compend Contin Educ Dent Suppl (28): S28, S31-25.

17. Al Shethri S, Matis BA, Cochran MA, Zekonis R, Stropes M, et al. (2003) A clinical evaluation of two in-office bleaching products. Oper Dent 28(5): 488-495.

18. United States Pharmacopeia Carbamide peroxide (2006) In: The United States Pharmacopeia 29th ed. United States Pharmacopial Convention, Inc, Rockville, Md, USA.

19. Matis BA, Gaiao U, Blackman D, Schultz FA, Eckert GJ, et al. (1999) In vivo degradation of bleaching gel used in whitening teeth. J Am Dent Assoc 130(2): 227-235.

20. Wattanapayungkul P, Matis BA, Cochran MA, Moore BK (1999) A clinical study of the effect of pellicle on the degradation of $10 \%$ carbamide peroxide within the first hour. Quintessence Int 30(11): 737-741.

21. Matis BA, Yousef M, Cochran MA, Eckert GJ (2002) Degradation of bleaching gels in vivo as a function of tray design and carbamide peroxide concentration. Oper Dent 27(1): 12-18.

22. Al-Qunaian TA, Matis BA, Cochran MA (2003) In vivo kinetics of bleaching gel with three-percent hydrogen peroxide within the first hour. Oper Dent 28(3): 236-241.

23. Alonso De La Peña V, Rodriguez Carreira A, Corral Aneiros R, López Ratón M, et al. (2013) A study of in vivo degradation of two vital home bleaching gels. Dent Mater J 32(4): 654-658.

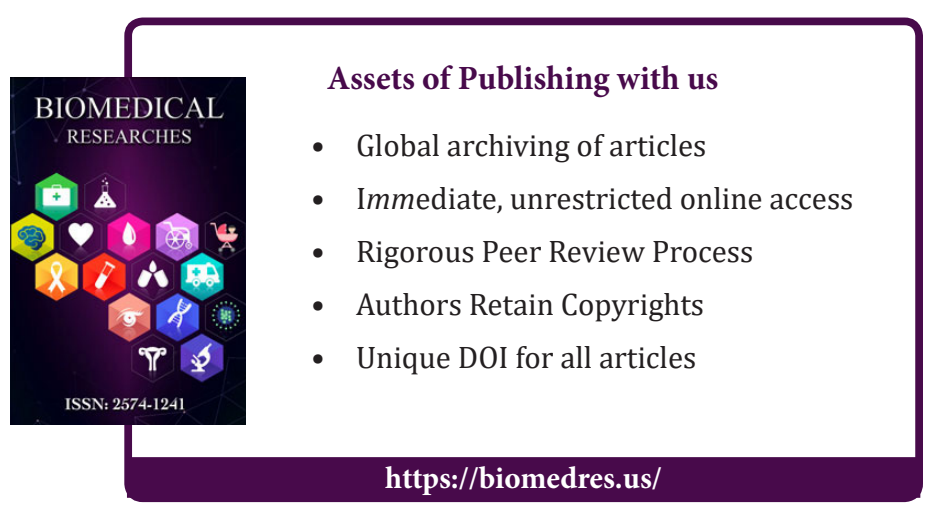

Cite this article: Francine K VM, Celso Afonso K J, Eduardo G R; Rubem Beraldo d S, Fernando Freitas P, Keiichi H. Storage Temperature Influences the Carbamide Peroxide Concentration of at Home Bleaching Agents. Biomed J Sci\&Tech Res 9(1)- 2018. BJSTR. MS.ID.001750. 